\title{
Case Study of a Blind Computer Graphics Student's Online Interactions
}

\author{
Deller James Ferreira, Federal University of Goiás, Brazil \\ Tatiane F. N. Melo, Federal University of Goiás, Brazil \\ Luciana Oliveira Berretta, Federal University of Goiás, Brazil
}

\begin{abstract}
Previous research points that computer-supported collaborative learning is an educational approach that suits blind students, because they have high verbal capacity. The authors believe that both sighted and blind students may gain from knowledge sharing, transactions on collaborative tasks, and being aware of distinct cognitive aspects, ideas, and activities, due to different behaviors, perceptions, and backgrounds. To unveil new insights concerning this assumption, they present an exploratory case study that provides an analysis of one blind undergraduate computer graphics student's online interactions during collaborative learning. They approached a qualitative technique to analyze results obtained from the blind student participation and interaction in discussions. The analysis of a blind student interactions, participation, and interaction patterns revealed emotional and deep relationships that implied in profitable interactions, knowledge construction, and better blind and sighted students' performance.
\end{abstract}

\section{KEYWORDS}

Blind and Sighted Students, Computer Graphics Students, Computer-Supported Collaborative Learning, Students' Interactions

\section{INTRODUCTION}

Accessibility raises many challenges and opportunities relevant to computer-supported collaborative learning that should be regarded. New technologies allow blind people to participate in online learning. We are now faced with educational demands that led us to rethink and expand our educational methods to embrace students with special needs.

Indeed, in the educational system, there are some students who need a singular teaching approach. In particular, blind people can benefit enormously from the significant social, cultural, economic, and educational opportunities of information and communication technologies. The Royal National Institute for the Blind stated "The Internet is one of the most significant communication developments since the invention of braille. For the first time ever, many blind and partially sighted people can have access to the same wealth of information as sighted people and on the same terms". 
However, blind people will benefit from the educational advantages of online learning as long as the computational systems and educational methods are designed appropriately. In general, little attention is devoted to students with disabilities despite the fact that they need more consideration (Pudaruth et al., 2017). Inclusive education "involves focusing on the individual needs of learners, helping them to overcome any barriers that may prevent them from reaching their potential" (Walker \& Logan, 2009). In this broad definition, any student requires some kind of assistance to enable them to reach their potential. So, an important issue is to identify the barriers that they need to overcome and the challenges the teachers need to surpass as well. We need to address the needs of the great number of blind learners, who commonly have had limited access to general education (Seo et al., 2017). There is a demand for investigations with the aim to unveil effective teaching and learning methods encompassing blind students.

On the other hand, blind people tend to develop other perceptual abilities that should be explored and managed to help other students. Some of the practices developed to accommodate students with special needs can often be of benefit for other students as well (Petrie \& Edwards, 2006; Dix, 2001). So that, all students within a classroom is able to learn effectively, regardless their differences. Thus, a more open investigation to be considered is identifying challenges as well as the opportunities underneath inclusive education.

Concerning computer-supported collaborative learning, previous research points out that blind students have high listening capacity. Collaborative learning is an appropriate educational method to promote the dialogical capacity of blind students (Najafi et al, 2012). Since blind students have not any vision they should be encouraged to use more their verbal ability. Collaborative learning method makes use of verbal capacity of blind students, promoting a conductive environment for learning. It can be applied to overcome the blind students visual limitation, because it takes advantage of their communications skills, like speed listening and reading.

Computer-supported collaborative learning approach allows students to discuss and exchange their points of view. It is a learning method in which students work together in small groups in order to get a common goal. Moreover, they are liable for their own learning, but also they are responsible for others' learning.

Collaborative learning needs to be structured in a way that group members know that they are interrelated with each other in a way that one cannot be successful unless everyone succeeds (Johnson \& Johnson, 1984). Collaborative learning setting must be established in order to make the students believe they sink or swim together.

When collaborative learning is solidly stated, one of its important features is to highlight that each group member's efforts are required and indispensable for the group to achieve their goals and also that each group member has a unique contribution to make to the joint effort. By doing so, a commitment to the success of group members emerges as well as one's own. A positive interdependence among students is the heart of collaborative learning.

Collaborative learning is significant to special education having the potential to cause a positive effect on problem solving capacity of blind students, because it is a matter of grouping students heterogeneously, understanding that the differences among students are advantageous, and also encompasses the acknowledgement that every student counts and is able to provide an unique contribution.

Many authors have defended the diversity of the group members (Acharya \& Devadatta, 2018; Zheng et al., 2018; Basadur, 2001) and have confirmed that students interacting in heterogeneous groups have better performance than in homogeneous groups. To confirm this assertion, the authors conducted experiments where students were divided into homogeneous groups, semi-homogeneous and heterogeneous, where tests were applied to each of the groups, and the heterogeneous groups performed better.

According to Janis (1971), if a group has members with similar views, decisions flow more easily, however, the effectiveness of the decisions may be impaired because different opinions, perspectives 
and methods cease to be analyzed because they are not displayed due to the homogeneity of the views of the members.

It seems to be an opportunity to intertwine the different perspectives of blind and sighted students, exploring the diversity inside the group. Also it can be profitable sighted students to be aware of blind students points of view to be able help and to be helped by them.

With respect to how students relate to each other, there are evidences that the more students are aware of others' behavior and perceptions and engage on the reasoning of other's students, they more benefit from collaborative learning arrangements (Gijlers et al, 2014).

Awareness is generally considered in terms of individuals' perception of others' activities and the status of others' work processes. Awareness in collaborative learning can be defined as the understanding of activities of other students, and thus gaining context for your own activity (Dourish and Bellotti, 1992) or students' perceptions and knowledge about the learning situation (Buder and Boemer, 2008). Based on that information the student is able to adjust his behavior.

The importance of people's level of awareness of one's own and others' activities for collaborative learning has been addressed thoroughly in the current literature. Gaver et al. (1991) conducted one of the earliest and most important studies on awareness in collaborative environments in their "ARKola" bottle plant simulation. They showed that awareness cues, depicting the overall status of the work as well as the individual participants' behaviors, had a large positive effect on task outcomes and the overall collaboration. An crucial factor to be considered in collaborative virtual environments is the way in which continuous awareness of others' activities allows students to manage their own activity in social situations in a flexible way and to predict actions of others' students (Benford et al. 1994).

Besides awareness, another decisive aspect in collaborative learning is transactivity. Transactivity is a term introduced from Berkovits and Gibbs (1993) and contextualized in collaborative learning by Teasley (1997). Transactivity means "reasoning operating on the reasoning of the other". Students converge to a good solution in collaborative problem-solving settings, when they engage in a transactive discussion and critically evaluate different perspectives based on their assumptions before they reach a consensus about the solution (Rummel et al, 2009).

Computer-supported collaborative learning seems to be an adequate method for blind students to engage in productive interactions. If sighted learners have the opportunity to operate on the reasoning of blind learning partners or blind students operate on the reasoning of sighted group partners, they will have room to integrate and integrate one another's distinct point of views with the objective to construct knowledge by means of productive interactions.

Despite computer-supported collaborative learning involves tools that mediate thinking and learning and it is proper to facilitate students' discussions; these artifacts have not been frequently applied to boost interactions among blind and sighted students. Blind students have capacities and talents that can be unveiled by collaborative learning.

Both sighted and blind students may gain from knowledge sharing and transactions on joint tasks, as well as being awareness of distinct cognitive aspects, ideas, and activities due to different behaviors, perceptions and backgrounds. In order to unveil new insights concerning this assumption, we present in this paper an analysis of blind and sighted undergraduate computer graphics students' online interactions during collaborative learning. This analysis encompasses participation and interaction patterns among students and their joint knowledge construction.

\section{RELATED WORK}

According to Ivan Sutherland (1970), a computer display can be seen as a window in Alice's wonderland in with a programmer can depict either objects that obey well-known natural rules or purely imaginary objects that follow laws he/she has written into his/her program.

Considering computer graphics, these natural rules and imaginary laws requires bi or threedimensional scenes to be modeled and visualized by means of mathematical models. Undergraduate 
computer graphics courses content covers learning these mathematical models along with their algorithms.

Many research works have shown that collaborative learning can contribute positively to students' mathematical learning (Araujo et al., 2018; Clark et al., 2014; Stahl, 2009) and, in particular, in mathematical modeling situations (Blum \& Ferry, 2009). In the context of mathematical modeling tasks, other students' interpretations can be useful in the meaning making process of the student. Questioning and challenging new ideas are effective when group members invite and listen to others' ideas and reflect on them. Also, when the students make constant and conscious effort to share meanings, the group move towards collective mathematical understanding (Hernandez- Martinez \& Harth, 2014).

According to Terwel (2011), from the perspective of teaching methods in mathematics, positive outcomes may be expected from group assignments. In a learning setting, where different cognitive levels and distinct experiences are brought together, the students are offered the possibility to strengthen their mathematical problem-solving capacity. Besides, the students can collaboratively inquire and elicit active processing that generate new knowledge.

In addition to learning mathematics, a computer graphics course including blind students involves special educational strategies. Studies on minority students are scarce, specially, in respect to collaborative learning. Najafi et al (2012) conducted a successful and pioneering research addressing collaborative learning for mathematics education for blind people. Even though collaborative learning has proven to be relevant to inclusive education, only one similar research was found in literature. Swan (2017) reported experiences of blind and visually impaired students in math courses at university level, concluding that blind students actively participated in the learning process, regardless of their visual disabilities, and had a positive collaborative learning experience. Furthermore, a literature review revealed no study involving computer graphics, or even other computer science subject, embracing the application of collaborative learning to blind students.

There are some recent research studies that cover the accessibility of e-learning systems for blind users (Tapu et al., 2017; Snodgrass et al, 2016; Buzzi et al., 2009; Calvo et al., 2011; Calvo et al., 2014), focusing on accessibility-limiting barriers for blind users. However, these works are restricted to the specific causes of accessibility problems in an educational environment that limit blind human-computer interactions. In contrast, the focus of this work is students' interactions mediated by the computer.

Thus, a work addressing an investigation about the challenges and opportunities of computersupported collaborative learning, approaching participation and interaction patterns among blind and sighted students (student-student interactions) and their joint knowledge construction in a computer graphics undergraduate course is relevant and worthwhile.

\section{RESEARCH QUESTIONS}

There is scarce literature focusing of the specific topic of teaching computer graphics to blind students. The few research existent does not focus on teaching and leaning methods, but on technological tools such as haptic interfaces and other computational tools to allow blind students perception of bi or three-dimensional objects (Moll \& Pysander, 2013; Sodhi et al., 2013).

More generally, we can say that there are few works focusing teaching computer science subjects to blind students. This gap in the literature results in no documentation of best practices or even reports on what does not seems to work. Mostly, computer science teachers are not well prepared or have no previous experience in teaching to a bind student.

In this context, the aim is to investigate the application of collaborative learning strategy in an undergraduate computer graphics course, bringing together blind and sighted students. So, the main research question of this work is: 
- What challenges and opportunities can we face when we engage blind and sighted users in computer-supported collaborative learning during an undergraduate computer graphics course?

In trying to answer this question this is broken down in the following research questions:

RQ1. What have the participation patterns in discussions revealed?

RQ2. What have the interaction patterns among the students revealed?

RQ3. To what extent have the students constructed knowledge collaboratively?

\section{The Study}

This study is characterized as an exploratory case study, where the goal is to investigate students' interactions and knowledge construction. In order to answer the research questions of this work, we conducted a study where we applied a qualitative approach to analyze results obtained from the students' online interactions. We present the data analysis concerning the effects of computer-supported collaborative learning as an educational method involving blind and sighted students, taking into account students' excerpts and students' interactions during the classes. The two teachers involved were also the researchers that performed the study.

\section{Course Description}

The case study was run on a computer graphic undergraduate course. The course duration was one semester. The course content covered was bi-dimensional (2D) and tri-dimensional (3D) geometrical transformations and compositions, the drawing of the curves, lines, circumferences and ellipses, 2D clipping, polygons filling, geometric projections, geometric modeling, hidden surface algorithms, and illumination models.

\section{Participants Profile}

During the case study the blind student and sighted students were computer science undergraduate students coursing their last academic year. The blind student is blind from birth, proficient in Braille, very familiar with the Jaws screen reader, and very skilled when dealing with computational interfaces, computing systems and programming.

\section{Procedures and Tools}

Some extra attention was given to the blind student in laboratory and classroom. However, the blind student attended the same classes, was taught the same materials, and participated on the same group activities that presupposed discussions via forums at Moodle platform, using Jaws screen reader. The course evaluation was the same for all students and was based on these group activities.

2D and 3D artifacts were developed to allow the blind student an understanding of the mathematical models and their mappings to its corresponding computer graphics algorithms. Computer graphics algorithms were implemented using the OpenGL application. 2D artifacts were made using glue and 3D artifacts were made using paperboard, glue, and strings. The students used the 2D and $3 \mathrm{D}$ artifacts during all tasks. The teachers elaborated six collaborative activities, described in Table 1.

\section{Learning Outcome Measurements}

In this work we took advantage of qualitative measure to analyze students' discussions. A qualitative analysis makes possible to delineate considering the interaction and participation students' patterns.

The coding scheme used to code and analyze learner's online messages were Newman, Webb and Cochrane's adapted model (1996) described by 10 categories. Newman, Webb and Cochrane's adapted model was chosen because it covers key aspects of the epistemic quality of interactions, 
Activity 1 . The students were asked to discuss and perform collaboratively thirty tasks related to $2 \mathrm{D}$ and $3 \mathrm{D}$ transformations conceptual understanding.

Activity 2. The students went to the lab and discussed in groups while using OpenGL to implement seven algorithms related to $2 \mathrm{D}$ and $3 \mathrm{D}$ transformations and transformations compositions.

Activity 3 . The teachers asked each group to discuss concepts involving continuous and discrete mathematical models involving line drawing and to discuss while using the OpenGL to implement an algorithm to draw lines.

Activity 4 . The teachers promoted a step-by-step discussion about scan-line mathematical visualization technique and algorithm to fill convex or concave polygons, containing or not holes.

Activity 5 . The teachers fomented group discussions concerning polygon 2D clipping technique.

Activity 6 . The teacher asked each group to choose a computer graphics subject to be orally presented. All group conceptual discussions were made via Forums at Moodle platform.

unveiling how students relate to concepts to be learned and widen and deepen the knowledge. This model allows the detection of profitable students' interactions from a socio-cognitive point of view.

Following we describe Newman, Webb and Cochrane's adapted model.

Category 1. Relevance: Relevant states or diversions.

Category 2. Importance: Important points and issues or unimportant points and trivial issues.

Category 3. Novelty, new info, ideas, and solutions: New problem related information or repeating what has been said.

Category 4. Bringing outside knowledge or experience to bear on problem: Drawing on personal experience or sticking to prejudice or assumptions.

Category 5. Ambiguities; clarified or confused: Clear statements or confused statements.

Category 6. Linking ideas, interpretation: Linking facts, ideas and notions or repeating information without making inferences or offering an interpretation.

Category 7. Justification: Providing proof or examples or irrelevant or obscuring questions or examples.

Category 8. Critical assessment: Critical assessment or evaluation of own or others' contribution or uncritical acceptance or unreasoned rejection.

Category 9. Practical utility (grounding): Relate possible solutions to familiar situation or discuss in a vacuum.

Category 10. Width of understanding (complete picture): Widen discussion or narrow discussion.

The teachers involved in this study, discussed what effects they have observed using this method in their classrooms and laboratory classes. We also developed a questionnaire, for teachers that have taught the blind student in other courses, searching for more information about his learning context. Following we describe the questionnaire answered by other courses teachers.

1. What was challenging for you?

2. What was an opportunity for you?

3. What obstacles the student could not surpass?

4. Has the student surprised you in some way, going beyond your expectations? When?

5. Were you prepared to teach a blind student? Have you adapted something in your course?

6. What did you learn?

7. What is your overall opinion about this teaching experience? 


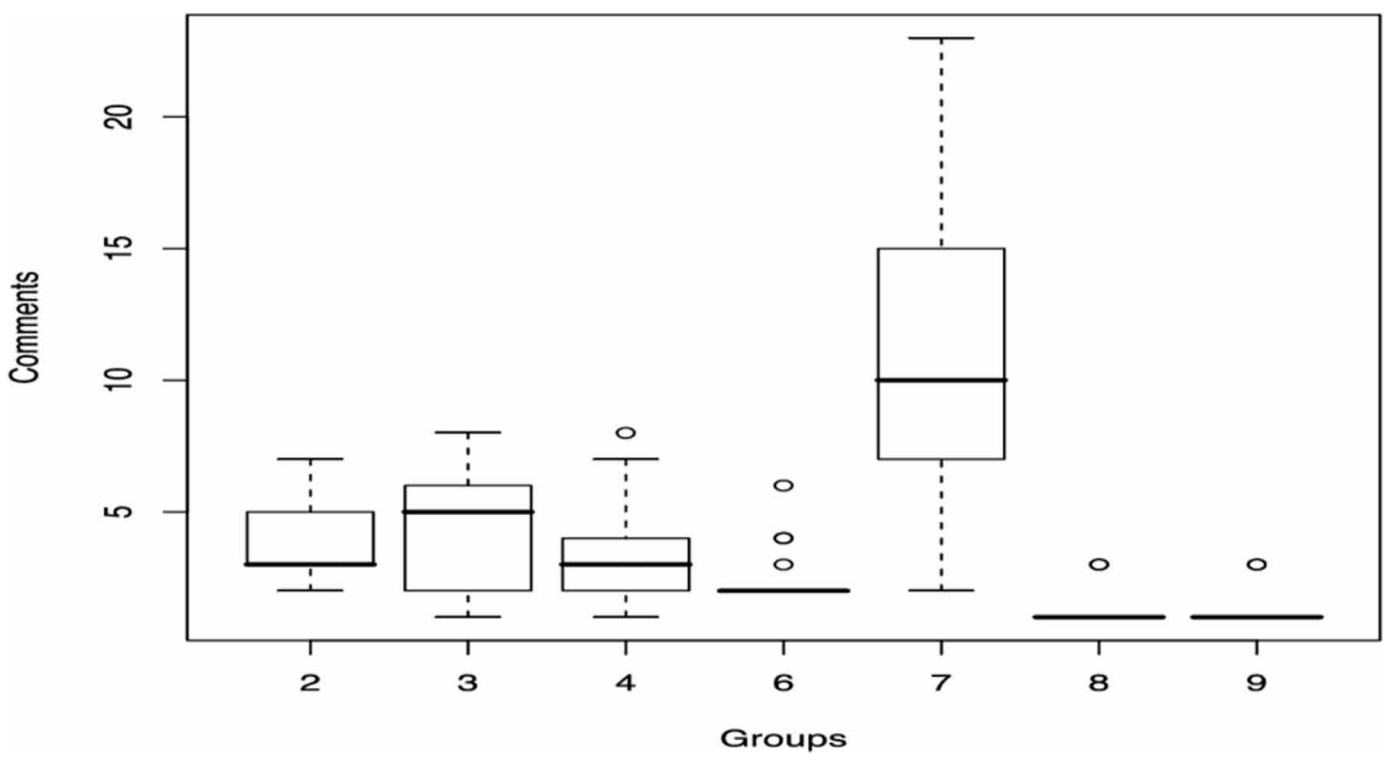

\section{Results}

Students' online messages were used as a data source that provided us with information about students' collaborative knowledge building process, regarding epistemic, interactive, and emotional aspects.

All groups were randomly formed. The blind student was randomly assigned to Group 7 . We performed comparisons between Group 7 and other groups and between the blind student and other students to check differences between conditions in amount and quality of utterances.

Students from Group 1 dropped the course; the students did not perform the tasks. So, Group 1 was excluded from analysis.

A comparison of the depth and breadth of the topics discussed by the students and a sociocognitive analysis respond the research question RQ3, while an interactive analysis answers the research questions RQ1 and RQ2.

\section{Comparison of the Depth and Breadth of the Topics}

We compared results between Group 7 and other groups regarding how was the progression of task related ideas (depth of topics) and the generation of new ideas (breadth of topics) in online discussions.

The number of comments in Group 7 was higher than in other groups. Figure 1 comparatively shows the number of comments per topic.

The discussions were deeper in Group 7 than in other groups. Analysis of discussions revealed that the arguments in commented topics in Group 7 were stronger. The blind student as well as the other students in the group justified their opinions and defended their thoughts by means of a democratic and argumentative discourse. There has been a progression of ideas and the arguments were grounded, clarified, judged and developed.

But, there was a greater concern with the blind student understanding. The students expressed themselves with the intention to elucidate the blind student doubts. Besides, the blind student initiated all the commented topics. The blind student initiated all discussions and the rest of the group advanced his ideas. The students only engaged in his perspective, showing that he was the focus of the group.

The other students also provided knowledge to the blind student, giving new information, technical advice, contextual advice, i.e., advice for task solving, but not exploring explanations about their own 
concerns. We could notice that the blind student had his understanding favored by other students, showing a growing understanding of concepts and being able to contribute actively in all tasks.

Comparing the breadth of the topics discussed, the generation of new ideas in Group 7 was as wide as in other groups, but the discussions that evolved from them were wider in other groups. Online messages revealed that regarding the generation of new ideas, there is a reasonable number of new perspectives provided by the Group 7 components that were disregarded. Only the blind student's ideas and concerns were given attention.

There was Group 7 members' knowledge co-construction on blind student ideas, by means of elaboration, criteria establishment, and relevance analysis, but there was no integration with their own ideas or other group component's ideas. Sometimes, students proposed modifications in blind student's proposals, but never regarding their initial contributions. Blind students knowledge has been rebutted to a deeper knowledge, but the students elaborated on blind student's ideas, giving up their previous own ideas.

Thus, Group 7 shows an asymmetry of breadth and depth in knowledge construction, that is clearly a disadvantage. But, this can also be seen as an advantage from the point of view of meaning making and knowledge advancement, because, there were further explanation and development of blind student's arguments. Longer discussions led the students to a better results and better understanding.

This can be seen as evidence that socio-emotional and motivational aspects influenced students' interactions during all collaborative tasks. The students in Group 7 showed a positive affect towards the blind students, exhibiting concern for his learning.

On the other hand, the perspectives from other students were not explored and compared to the blind student perspective. This is not an advantage because the divergence of ideas or different points of views are profitable to knowledge production.

\section{Socio-Cognitive Analysis}

Unimportant, irrelevant, and ambiguous online messages were not regarded in this research, because section 5.1 provides comparisons with respect to the number of important, relevant and unambiguous messages inside different groups. Thus, we eliminated categories 1, 2, and 5 from Newman, Webb and Cochrane's code scheme.

In Figure 2, we have the Box Plot of the number of posts per category. We note in this figure that, regarding Category 3, the smallest number of messages in Group 7 was 3 and the highest was 11 , with a median of 8 . Graphically, the Group 7 stood out from the others, followed by groups 3 and 4 , respectively.

Categories 2 to 8 aforementioned are related to quality of epistemic aspect of collaborations, being indicators of quality of online messages, depicting individual and group solutions. Taking into account the statistical results form data, in categories 2 to 8, Group 7 excelled all other groups in all categories, except Group 2 in categories 4 and 7. So, Group 7 was more well performing than the other groups.

We scrutinized online interactions searching for some evidence on the role of interactions in students' socio-cognition during collaborative tasks. This analysis unveiled insights about quality of group solutions, the effect of collaborations on individual solutions, and aspects of the computer graphics subject that the blind student were successful or not.

Concerning the quality of group solutions, some findings show that the top-performing group (Group 7) was the most active at the knowledge level, engaging themselves in high-level sociocognitive activities. The collaborations allowed the blind student and other participants gained knowledge about their partners' awareness and expertise. Besides, Group 7 interactions indicated a shared problem solving, where knowledge construction was related to each other's reasoning, where ideas were shared, clarified, and developed.

The blind student exceeded our expectations. Using Jaws technology, he was able to interact with others as equal and learn computer graphics, being even better that sighted students sometimes. For all 
Figure 2. Box Plot of the number of posts per category

Category 3: Novelty

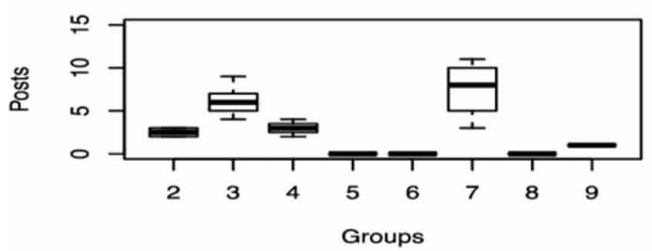

Category 6: Linking ideas

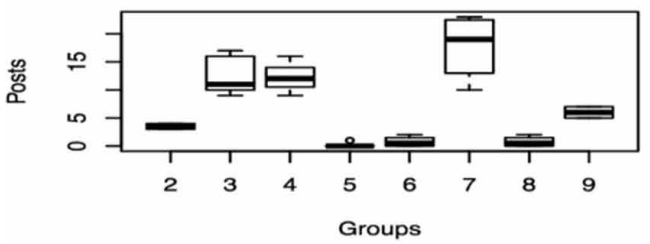

Category 8: Critical Assesment

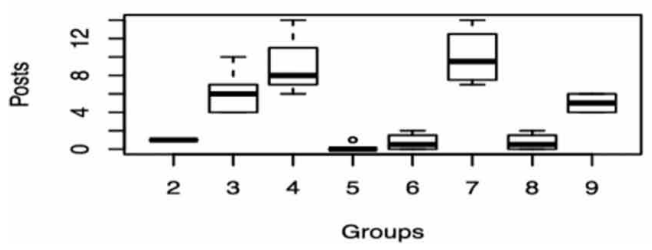

Category 4: Bringing outside Kowledge

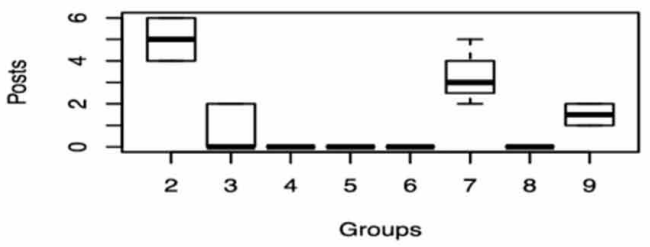

Category 7: Justification

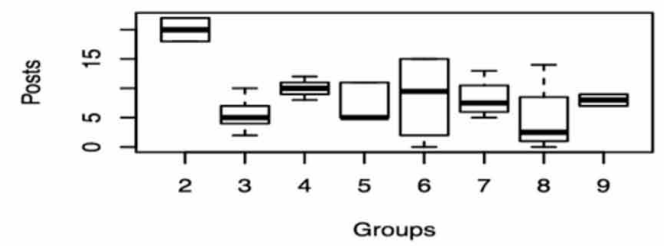

students, individual contributions emerged in discourse and were shared among other students in the group, becoming part their individual knowledge structures as a result of exchanges. Their solution choices were based on deep analysis of arguments. There was an ongoing reflection concerning points of view. The students have gone deep in their arguments. All students in Group 7 contributed to the group discussion, summing up ideas to the final solution.

Collaborations strongly influenced the learning of the blind student in computer graphics. He relied to some extent on the complementary expertize of their partners to make sense of the learning tasks and to design a joint problem solution. However, the blind student was the most productive, having the main contributions for new ideas. He was the focus of discovery, having his solutions adjusted and improved. The knowledge used for building the solutions was not distributed among members of the group. Differently from Group 7, in the other groups there were summarizing and combining. The students summarized previous discussions, discovering a solution based on group activities deriving from different or even divergent points of view.

Pondering the effect of collaborations on individual solutions, about the quality of the blind student solution, we found evidence in online discussions that he went beyond his previous ideas. The blind student demonstrated an extrapolation of his previous ideas as well as overcame initial difficulties. Besides, there were indications that the more students built on the reasoning of the blind user, the more he benefited from the collaborative learning arrangement.

Thus, we can conclude that there was knowledge transfer from group to individual and from individual to group. By a viewpoint, the blind student clarified doubts and went deeper in knowledge building, largely through interaction with members of his group. In contrast, students heeded and extended the blind student concerns and contributions. The students operated on the reasoning of the blind student, elaborating his perspectives in order to jointly make new connections and interpretations. 
Figure 3. Box plot of the degree of interactivity of each student with the other components of the group

Group 3

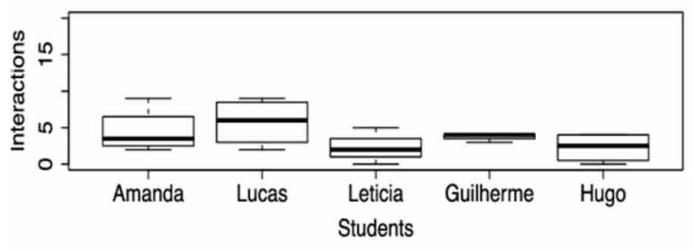

Group 5

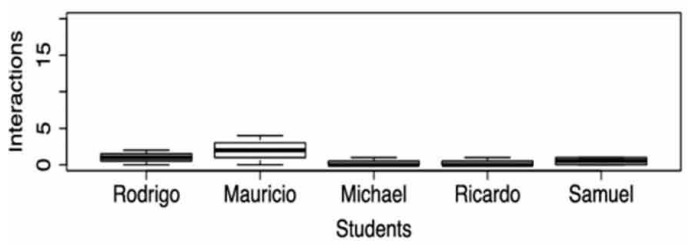

Group 7

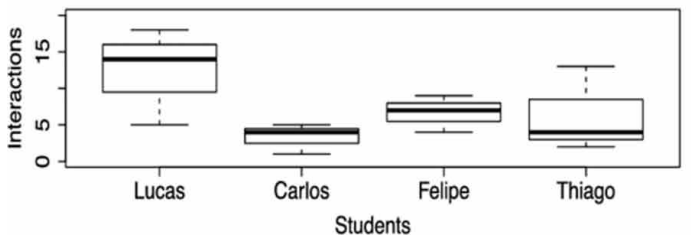

Group 4

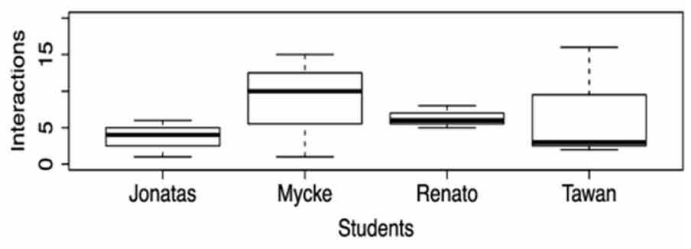

Group 6

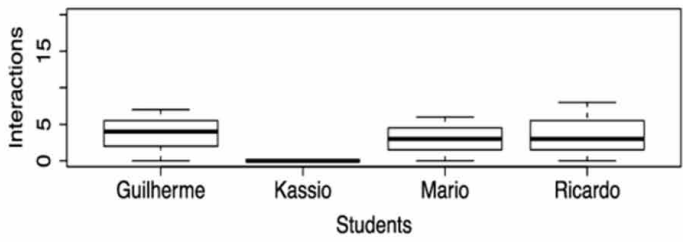

Group 8

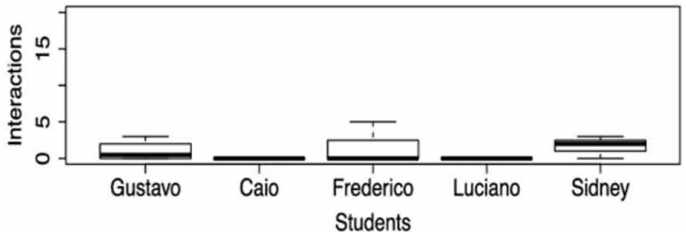

Observing computer graphics topics that the blind student was successful or not, the blind student showed a great facility in learning mathematical models, their discretization and corresponding algorithms. He also exhibited readiness to understand the techniques ray tracing and zoom. Nevertheless, the blind student was not able to understand aspects related to visual perception, such as $3 \mathrm{D}$ projections and $2 \mathrm{D}$ morphing objects.

It is worth noting that, traditionally; students in computer graphics course have a hard time with $3 \mathrm{D}$ visualization and mathematical abstractions. Interestingly, the blind student far surpassed the other students in this regard.

\section{Interactivity Analysis}

Figure 3 presents the Box Plot comparing interactivity degree between each student and other components of the group. The Box Plot depicts how much each student interacted with other members of the group. In Group 3, Amanda's median of interactions with others is 3. Also in this group, William interacted on average 6 times, followed by Hugo (4 times). In Group 4, Renato had the highest median of interactions ( 15 times), followed by Tawan (6 interactions) and Mycke ( 3 interactions). A low number of interactions was detected in groups 5 and 8. In Group 7, Lucas (the blind students) had the higher median (9 interactions), followed by Philip and Charles ( 5 interactions) and Thiago (4 interactions).

In Figures 4 and 5, we have the percentage of interactions within each group. Group 9 is not in figure 5 because there were only two students in this group. We note that within the Group 3 the largest number of interactions occurred with the student Guilherme (31\%). In Group 4, 34\% of the interactions were made with Mycke. Furthermore, most of the interactions of groups 5, 6, 7 and 8 were made with Mauricio (50\%), Guilherme (36\%), Lucas (43\%) and Sidney (44\%), respectively.

In Figure 6, we have the percentage of students' interactions with relation to the total number of interactions. We note that there was no interaction (0\%) with Kassio (Group 6), Gaius (Group 8) 
Figure 4. Percentages of interactions within each group (Groups 3, 4, 5, and 6)

Group 3

:

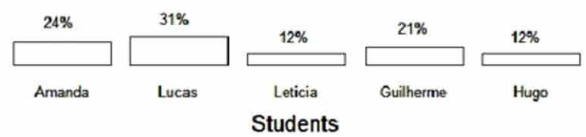

Group 5

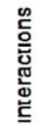

Group 4

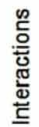

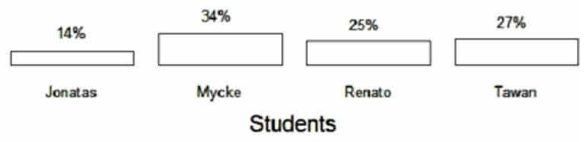

Group 6

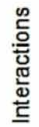
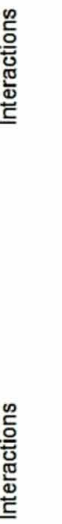

Figure 5. Percentages of interactions within groups (Groups 7, 8, and 9)

Group 7

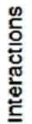
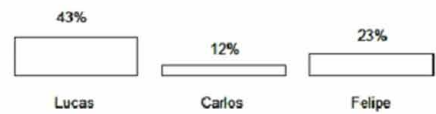

Students

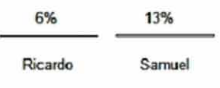

Group 9

气ั

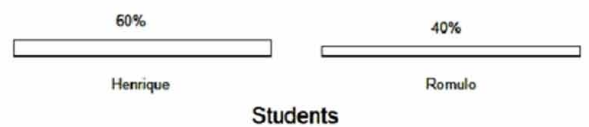

and Luciano (Group 8). We also note that the highest number of interactions was made with Lucas (11\% - Group 7), followed by Mycke (8\% - Group 4) and Lucas (7\% - Group 3).

The data from online interactions shows that Group 7 was the most interactive group. Moreover, there was an asymmetry of interactions in Group 7. The blind student was more interactive than the other students in his group and concentrated others' interactions. 

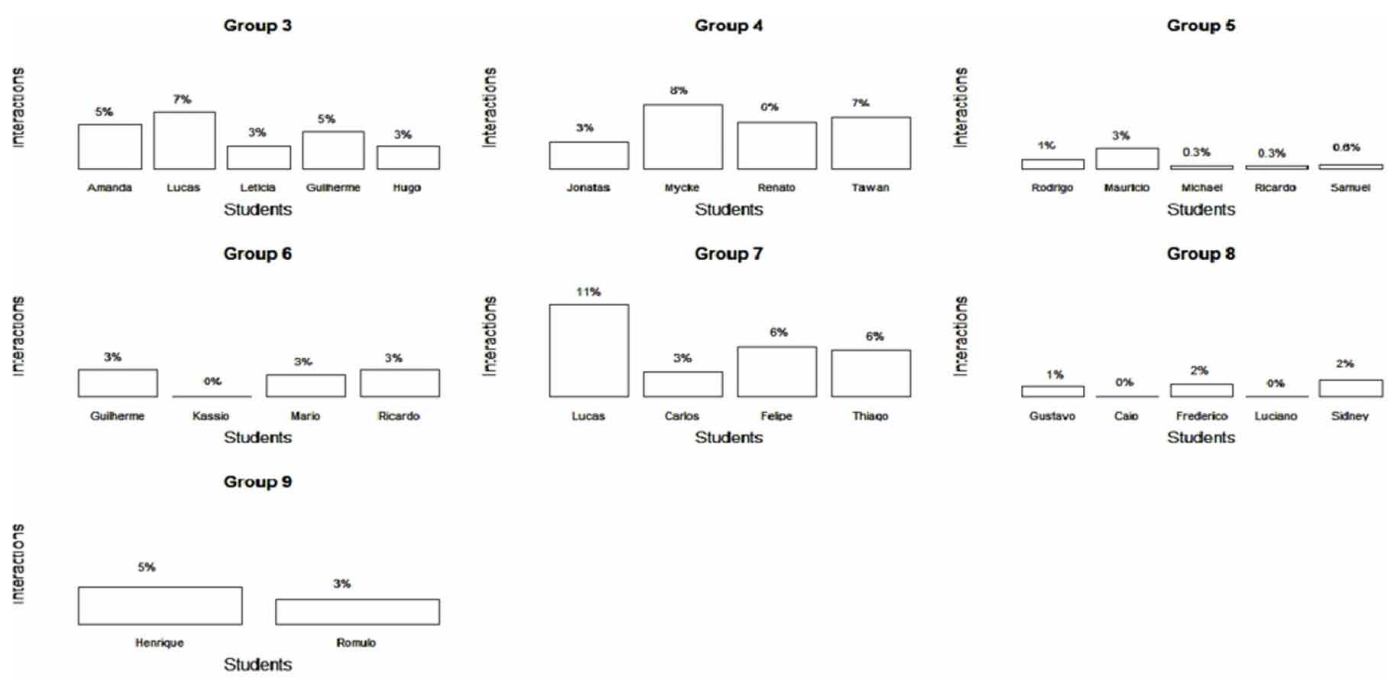

A deeper investigation on online messages showed some possible causes of Group 7 featured interactions and how the interactions happened. First, we noticed how the participation of the blind student influenced the participation of the other students in his group. Second, the students' excerpts revealed a positive affect toward the blind student. Thus, leading them to an increased engagement and efforts in helping him and implying well succeed group interactions. Third, Group 7 has no unproductive interaction like other groups, in which there were lack of responses to others and monologues.

Focusing on evidences in students' excerpts that clarify how the participation of the blind student influenced the participation of the other students in his group, we found that elicitation of the blind student led to other students' externalization of information and initiatives toward knowledge construction. We notice that not only the blind student interacted with $2 \mathrm{D}$ and 3D artifacts. All the students interacted with 2D and 3D artifacts. They also interacted with each other regarding 2D and 3D artifacts, which led to better awareness and joint attention on tasks. Besides, the students in Group 7 overcame easily their difficulty of 3D abstractions unlike students in other groups.

The blind student invited a reaction from their learning partners. This is done by asking questions and asking for critics and suggestions about their proposals. The blind student introduced new openings, asking for specific knowledge, asking about technical issues, bringing in new information in question form, questioning his reasoning about knowledge, and expressing an opinion in question form.

The students in Group 7 reacted to the blind student elicitations providing support for shared knowledge construction, by means of advice, explanations about other situations, opinions, suggestions, or clarification about an upcoming activity. They were committed with the blind student and the group knowledge advancement.

Regarding awareness and joint attention, the students in Group 7 could see the tasks from the blind student perspective, being aware of his limitations and insights. Interactions via 2D and 3D objects made the students to benefit from sharing focus on the joint activities, facilitating sharing and convergence. We notice evidence that students' joint interactions with $2 \mathrm{D}$ an 3D artifacts served as a conductor to a deeper socio-cognitive shared understanding and better performance and that awareness unleashed a dynamic learning process, where interaction with the blind student has proved to be essential. 
Another important issue unveiled by analysis of online messages in Group 7 was other students' strong emotional attachment to the blind student. Group members' appraisal of the blind student situation dictated the emotional climate. The students enacted to a socio-emotional balance and interdependence by means of positive affect and sense of unity as a group. Sensitive relationships among students were established. This fact influenced other aspects like participation and quality of interactions.

The occurrence of a socio-emotional bond can be used to explain why Group 7 was more successful and surpassed other groups regarding the quality of interactions. Motivational and emotional processes, at both the individual and group levels, influenced productively socio-cognitive processes and interactions.

Differently from Group 7, some other groups manifested a negative affect, exhibiting lack of motivation and willingness to participate in collaborative tasks. In some groups there were no reaction and no externalization. Some students either responded to questions or other form of elicitation of their learning partners neither outlined their knowledge with reference to earlier messages. Also, there were some students that repeated their own thoughts and positions, ignoring others' suggestions without evolving their ideas.

In this study, motivational issues were particularly central in collaborative learning in Group 7, where the socio-emotional atmosphere was strongly present. A positive group's socio-emotional atmosphere acted as essential feature of a well-working group. The students positively attached to the group activities. So, they more likely overcame challenges productively. The students were confronted with a complex system of influences between emotions, collaboration and learning. The mark of successful collaborative learning was a balance among socio-cognitive and socio-emotional processes.

\section{CONCLUSION}

A case study research conducted during one semester in a computer graphics course has given us insight into the application of collaborative learning to blind students, indicating that this practice helped the blind student to be successful in problem solving, as well as helped sighted students to have an enhanced awareness and go deeper in knowledge. Collaborative learning was beneficial to the blind student computer graphics learning and a good and advantageous experience to sighted students.

From the analysis of discussions, examinations of students' interactions, participation and interaction patterns revealed emotional and deep relationships that implied in profitable interactions, knowledge construction, and better performance. Only one negative aspect was encountered. The students' interactions were concentrated on the blind student. This fact led to a narrow development, inhibiting the explorations of many perspectives. The knowledge construction was more vertical than lateral.

A significant contribution of this work is to enlighten teachers in respect to educational methods that have the potential to deal with opportunities and limitations raised by accessibility issues. This research motivates teacher to go beyond traditional learning and conceive collaborative learning as an alternative method. In practical terms, the results of this study can be used to assist in designing instructional practices for blind people.

To conclude, in the scenario of teaching computer graphics in a cohort having a blind student, collaborative learning was effective, enjoyable, and not about outperforming others, but about being aware and directing one's own and one's learning partners' understanding, interests and feelings towards the group success. 


\section{REFERENCES}

Acharya, A., \& Sinha, D. (2018). A "Mixed" Strategy for Collaborative Group Formation and Its Learning Outcomes. Journal of Educational Technology Systems, O(4), 1-23. doi:10.1177/0047239517749246

Arujo, Z., Orril, C. H., \& Jacobson, E. (2018). Examining the design features of a communication-rich, problemcentred mathematics professional development. International Journal of Mathematical Education in Science and Technology, 49(3), 323-340. doi:10.1080/0020739X.2017.1373153

Basadur, M., \& Head, M. (2001). Team performance and satisfaction: A link to cognitive style within a process framework. The Journal of Creative Behavior, 35(4), 227-248. doi:10.1002/j.2162-6057.2001. tb01048.x

Benford, S., Bowers, J., Fahldn, L., Mariani, J., \& Rodden, T. (1994). Supporting Co-operative Work in Virtual Environments. The Computer Journal, 37(8), 653-668. doi:10.1093/comjnl/37.8.653

Berkowitz, M. W., \& Gibbs, J. C. (1983). Measuring the developmental features of moral discussion. MerrillPalmer Quarterly, 29(4), 399-410.

Blum, W., \& Borromeo, F. R. (2009). Mathematical modelling: Can it be taught and learnt? Journal of Mathematical Modelling and Applications., 1(1), 45-58.

Buzzi, M. C., Buzzi, M., \& Leporini, B. (2009). Accessing e-learning systems via screen reader: an example. In Human-Computer Interaction. Interacting in Various Application Domains (pp. 21-30). Springer Berlin Heidelberg. doi:10.1007/978-3-642-02583-9_3

Calvo, R., Iglesias, A., \& Moreno, L. (2011). Is Moodle Accessible for Visually Impaired People? In Web Information Systems and Technologies (pp. 207-220). Springer Berlin Heidelberg.

Calvo, R., Iglesias, A., \& Moreno, L. (2014). Accessibility barriers for users of screen readers in the Moodle learning content management system. Universal Access in the Information Society, 13(3), 315-327. doi:10.1007/ s10209-013-0314-3

Clark, K., James, A., \& Montelle, C. (2014). We definitely wouldn't be able to solve it all by ourselves, but together...: Group synergy in tertiary students' problem-solving practices. Research in Mathematics Education, 16(3), 306-323. doi:10.1080/14794802.2014.950687

Dix, A. (2001, Jan.). The right mind? ACM SIGCHI Bulletin.

Dourish, P., \& Bellotti, V. (1992). Awareness and coordination in shared workspaces. Paper presented at the ACM Conference on Computer-Supported Cooperative Work, Toronto.

Fisher, R. A. (1970). Statistical Methods for Research Workers (14 ${ }^{\text {th }}$ ed.). Oliver \& Boyd.

Gaver, W. W. (1991). Sound support for collaboration. In L. J. Bannon, M. Robinson, \& K. Schmidt (Eds.), Proceedings of European Conference on Computer-Supported Cooperative Work (ECSCW). Dordrecht, The Netherlands: Kluwer Academic Publishers.

Gaver, W. W., Smith, R. N., \& O'Shea, T. (1991). Effective Sounds in Complex Systems: The ARKola Simulation. Proceedings of the ACM CHI 91 Human Factors in Computing Systems Conference, 85-90.

Gholamali, L. M., Afzali, L., Borhanzadeh, Sh., Afzali, F., \& Davoodi, M. (2011). The effect of cooperative learning on the social skills of first grade elementary school girls. Procedia.

Gijlers, H., Weinberger, A., Dijk, A. M., Bollen, A., \& Joolingen, A. (2014). Collaborative Learning in Mathematical Modeling Tasks. BERA CHAT Meeting.

Gokal, A. (1995). Cooperative Learning. Collaborative Learning Education.

Janis, I. L. (1971). Group Think. Psychology Today. 
Johnson, D. W., \& Johnson, R. T. (1984). Collaborative drawing on a shared digital canvas in elementary science education: The effects of script and task awareness support Circles of Learning. Washington, DC: Assoc. Supervision and Curriculum Dev. Computer-Supported Collaborative Learning. Advance online publication. doi:10.1007/s11412-013-9180-5

Moll, J., \& Pysander, E. (2013). A Haptic Tool for Group Work on Geometrical Concepts Engaging Blind and Sighted Pupils. Academic Press.

Najafi, M., Rostamy-Malkhalifeh, M., \& Amiripour, P. (2012). The Effect of efficiency of cooperative learning method on increasing blind students' perception of mathematical conceptions. Journal of Applied Mathematics, $8,57-63$.

Newman, D. R., Webb, B., \& Cochrane, C. (1996). A content analysis method to measure critical thinking in face-to-face and computer-supported group learning. University of Missouri-St. Louis.

Petrie, H., \& Edwards, A. (2006). Inclusive design and assistive technology as part of the HCI curriculum. Proceedings of HCI Educators Workshop, 23-24.

Pudaruth, S., Gunputh, R. P., \& Singh, U. G. (2017). Forgotten, excluded or included? Students with disabilities: A case study at the University of Mauritius. African Journal of Disability, 6, 359-365. doi:10.4102/ajod.v6i0.359 PMID:28936422

Rummel, N., Spada, H., \& Hauser, S. (2009). Learning to collaborate while being scripted or by observing a model. International Journal of Computer-Supported Collaborative Learning, 4(1), 69-92. doi:10.1007/ s11412-008-9054-4

Screen Reader, J. A. W. S. (2015). Freedom Scientific. Available from: http://www.freedomscientific.com/ Products/Blindness/JAWS

Seo, J. Y., AlQahtani, M., Ouyang, X., \& Marcela Borge, M. (2017). Embracing Learners With Visual Impairments in CSCL. Proceedings of CSCL Conference, 573-576.

Snodgrass, M. R., Israel, M., \& Reese, G. (2016). Instructional supports for students with disabilities in k-5 computing:Findings from a cross-case analysis. Computers \& Education, 100, 1-17. doi:10.1016/j. compedu.2016.04.011

Sodhi, R., Poupyrev, I., Glisson, M., \& Israr, A. (2013). AIREAL: Interactive Tactile Experiences in Free Air. ACM Transactions on Accessible Computing, 4, 1-10.

Stahl, G. (2009). Studying Virtual Math Teams. Springer Verlag.

Sutherland, I. E. (1970). Computer Displays. Scientific American, 222(6), 56-81. doi:10.1038/ scientificamerican0670-56

Swan, S. T. (2017). Experiences of Visually Impaired Students in Community College Math Courses (PhD dissertation). Morgan State University.

Tapu, R., Mocanu, B., \& Zaharia, T. (2017). A computer vision-based perception system for visually impaired. Multimedia Tools and Applications, 76(9), 11771-11807. doi:10.1007/s11042-016-3617-6

Teasley, S. (1997). Talking about reasoning: How important is the peer in peer collaboration? In L. B. Resnick, R. Säljö, C. Pontecorvo, \& B. Burge (Eds.), Discourse, tools and reasoning: Essays on situated cognition (pp. 361-384). Springer. doi:10.1007/978-3-662-03362-3_16

Terwel, J. (2011). Education for Innovation: The role of Arts and STEM Education. Cooperative learning and Mathematics Education: A happy marriage? VU University Amsterdam Faculty of Psychology and Education. Paper presented at the OECD / Franceworkshop, Paris.

Walker, L., \& Logan, A. (2009). Using digital technologies to promote inclusive practices in education. A Futurelab handbook. Bristol: Academic Press.

Zheng, Y., Li, C., Liu, S., \& Lu, W. (2018). An improved genetic approach for composing optimal collaborative learning groups. Knowledge-Based Systems, 139, 214-225. doi:10.1016/j.knosys.2017.10.022 
Deller James Ferreira received the degree in Bachelor of Mathematics from Fluminense Federal University in 1987, Masters in Computer Science from the Military Institute of Engineering in 1990, and Ph.D. in Education from Brasilia University in 2008. She made her post-doctorate in Education at University of Exeter in 2010. She is currently adjunct professor of the Institute of Informatics at Federal University of Goiás. She has experience in Informatics in Education, working mainly on the following theme: Computer Supported Collaborative Learning.

Tatiane F. N. Melo is graduated in Mathematics from the Federal University of Goiás (2002), received the master's degree in Statistics from the Federal University of Pernambuco (2004) and Ph.D. in Statistics from the University of São Paulo (2009), and post-doctorate in Statistics from the University of São Paulo (2015). 